\title{
Verbal fluency in school-aged Spanish children: analysis of clustering and switching organizational strategies, employing different semantic categories and letters
}

\author{
María P. Sánchez-López ${ }^{1,2, *}$, Francisco Román-Lapuente ${ }^{1,2}$ and María J. García-Rubioº,3 \\ 1 Faculty of Psychology, University of Murcia (Spain). \\ 2 Murcia Institute of Biomedical Research, IMIB-Arrixaca (Spain). \\ 3 International University of Valencia (Spain).
}

Título: Fluidez verbal en niños españoles en edad escolar: análisis de las estrategias organizativas de agrupación y cambio, empleando diferentes categorías semánticas y letras.

Resumen: La tarea de fluidez verbal es una medida de flexibilidad cognitiva y estrategia de búsqueda dentro del contenido léxico y semántico. Se evaluó el uso de estrategias organizativas en niños españoles sanos divididos en dos grupos: grupo 1 de niños más pequeños y grupo 2 de niños mayores introduciendo diferentes letras y categorías semánticas. La fluidez semántica fue mayor que la fluidez fonológica en ambos grupos de edad. Además, los niños mayores mostraron un mejor rendimiento de ambas fluencias que los niños más pequeños. A partir de los análisis fonológicos, los niños más pequeños evocaron más palabras con el grupo de letras PMR que con el de FAS. Además, se observó una mejora de la fluidez semántica asociada con la categoría animales frente a la categoría comidas y bebidas únicamente en el grupo de niños más pequeños. Con respecto a las estrategias organizativas, los niños mayores utilizaron más cambios, específicamente en el grupo FAS y más agrupamientos para la categoría de comidas o bebidas, en comparación con el grupo de niños mayores. Las relaciones entre el número de palabras evocadas y el número de agrupamientos y cambios para ambas tareas de VF fueron significativas y positivas. Estos datos sugieren que el tipo de letra y la categoría semántica empleada en la evaluación de la VF modulan el rendimiento en fluidez verbal en ambos grupos de edad.

Palabras clave: Fluidez verbal. Fluidez fonológica. Fluidez semántica. Agrupamiento. Cambio. Estrategias organizativas.

\section{Introduction}

The evaluation of verbal fluency (VF) is widely used in cognitive neuropsychological assessment of strategic search and retrieval processes from the lexicon and semantic memory (Raboutet et al., 2010; Riva, Nichelli, \& Devoti, 2000; Strauss, Sherman, \& Spreen, 2006). Verbal Fluency (VF) is defined as the number of words produced within a selected category in a limited period of time usually 60 seconds (Lezak, Howieson \& Loring, 2004, Ledoux et al., 2014).

The most common battery to assess semantic verbal fluency (SVF) and phonological verbal fluency (SVF) implies that subjects must produce the maximum of possible words belong to a specified semantic category (usually animals) (Troster et al., 1995; N`Kaoua, Lespinet, Barsse, Rougier, \& Claverie, 2001). Moreover, when subjects must generate as many words as possible beginning with a specified letter such as $\mathrm{F}, \mathrm{A}$, or $\mathrm{S}$ in a limited time, phonological verbal fluency (PVF) is evaluated (Filipetti \& Allegri, 2011; Troyer, 2000).

* Correspondence address [Dirección para correspondencia]: María del Pino Sánchez López. Faculty of Psychology, University of Murcia. 30100 Murcia (Spain). Email: mpinosl@,um.es

(Article received: 13-2-2020; revised: 19-7-2021; accepted: 20-7-2021)
Abstract: The verbal fluency task is a measure of cognitive flexibility and search strategy within the lexicon and semantic topic. The use of organizational strategies was tested in healthy Spanish children divided in two groups: group 1 of younger children and group 2 of older children introducing different letters and semantic categories. Semantic fluency was greater than phonological fluency in both age groups. In addition, older children showed better performance of both fluencies than younger children. From the phonological analyses, younger children evoked more word with the PMR letter group than with the FAS one. Moreover, an improvement of semantic fluency associated with the animal's category faced to meals and drink was observed only in the younger children group. In respect to organizational strategies, older children used more switches specifically in FAS group and more clusters for the meals or drinks category compared with the older children group. The relationships between the number of words evoked and the number of clusters and switches for both VF tasks were significant and positive. These data suggest that the type of letter and the semantic category employed in the VF evaluation modulate the verbal fluency performance in both groups of age.

Keywords: Verbal fluency. Phonological fluency. Semantic fluency. Clustering. Switching. Organizational strategies.
In both tasks, cognitive flexibility, the ability to use verbal search strategies and the degree of inhibition which use the evaluated person are explored (Azuma, 2004; Sauzèon, Lestage, Raboutet, N'Kaoua, \& Claverie, 2004). However, it is well known that each of these tasks requires different cognitive processes and brain areas. On the one hand, the SVF is determined by the verbal memory of the person and, therefore, the evocation of the words is done through semantic associations of the words already pronounced (Koren, Kofman \& Berger, 2005; Riva, Nichelli, \& Devoti, 2000). On the other hand, PVF performance requires the use of non-habitual strategies and especially depends on inhibition mechanism of incorrect responses which involves an extra cognitive effort that is not found in SVF (Koren, Kofman \& Berger, 2005; Riva et al., 2000). This difference explains the fact that the execution in the SVF tests is usually superior to the PVF performance (Riva et al., 2000, Matute et al., 2004). In respect to cerebral bases of them, results are no consistent. Pioneering studies proposed that PVF was associated with frontal cortex activity whereas SVF depends more on temporal cortical areas (Gourovitch et al., 1996, Milner et al., 1964). However, posterior studies showed that the frontal lobe is involved in both VF tasks (Schwartz \& Baldo, 2001, read the meta-analysis by Henry \& Crawford, 
2004), specifically phonological and semantic deficits were observed in patients with frontal lesions.

In addition, the performance of both fluencies involves the use of strategies such as groupings and jumps (Baldo et al., 2001; Troyer, 2000). The first strategy is described as the generation of sets of semantically associated words (semantic clusters) or phonologically (phonologic clusters). The second strategy refers to the moment in which the subject feels a category as exhausted, desists and changes to another category (jumps), at both semantic and phonological levels. Previous studies explored the cognitive processes associated with both strategies and concluded that groupings depend on the state of semantic memory, while jumps depend on executive components such as the subject's cognitive flexibility, mental search ability, degree of inhibition, and the ability to modify their responses in the course of the evaluation; without remaining stuck in a category (Sauzèon et al., 2004; Troyer, 2000).

Numerous factors have been associated with performance on VF, but in the case of children the most significant variable is age (Beltrán Dulcey \& Solís-Uribe, 2012; García et al., 2012; Lozano \& Ostrosky-Solís, 2006; Malloy-Diniz et al., 2007; Oliveira, Mograbi, Gabrig \& Charchat Fichman, 2016; Nieto, Galtier, Barroso, \& Espinosa, 2008). Previous studies demonstrated that the older children perform better on VF probably due to maturational processes of the frontal lobe (Brocki and Bohlin, 2004; García et al., 2012; Marino, Acosta-Mesas \& Zorza, 2011; Marino \& Díaz-Fajreldines, 2011; Matute et al., 2004; Sauzéon, et al., 2004). Specifically, several studies showed that the optimal development of frontal zones leads to an improvement in executive functions, which contributes to a better performance in VF tasks, especially in PVF tasks that depend more on these cognitive functions (Klenberg, Korkman, \& LahtiNuuttila, 2001; Korkman, Kemp, \& Kirk, 2001). These findings usually come from studies with pediatric patients suffering from neurodevelopmental disorders. In patients with attention deficit disorder, a relationship between deficits in VF and maturational brain problems has been found (Marchetta, Hurks, Krabbendam \& Jolles, 2008, Tucha et al., 2005). In general, it has been found that this type of patient has difficulties in inhibiting responses in PVF tasks (Sergeant et al., 2002), and also in SVF exercises (Fischer, Barkley, Edelbrock, \& Smallish, 1990; Tucha et al., 2005), obtaining a large number of errors and repetitions compared to the healthy population. In addition, these skills have been explored in other types of patients: children with dyslexia (Mielnik, Lockiewicz \& Bogdanowicz, 2015; Smith-Spark et al., 2017), with autism (Begeer et al., 2014), and with aphasia (Catani et al., 2013).

Furthermore, studies focused on the pediatric population without pathology are dedicated preferentially to find normative data of PVF and SVF from different countries: The United States (Prigatano, Gray \& Lomay, 2008), Switzerland (Tallberg et al. al., 2011), Holland (Van der Elst et al., 2011), Spain (García et al., 2012) and Brazil (Malloy-Diniz et al.,
2007), among others. However, no attention has been paid to analyze the strategies of grouping and jumps present in the VF of Spanish children. From the best of our knowledge, there is only one study which explored these strategies in this kind of sample (Nieto, Galtier, Barroso \& Espinosa, 2008). Specifically, Nieto, Galtier, Barroso and Espinosa (2008) evaluated SVF with the category of animals and the PVF with the letters F, A, M, in different age groups (group 1: 6-7 years group 2: 8-9 years, group 3: 10-11 years). In this work, older children (group 3) showed higher strategies abilities obtaining better FV performance compared to others groups (Nieto, Galtier, Barroso \& Espinosa, 2008). But, in our opinion their results are limited for two reasons. Firstly, F, A, M letters were used in the PVF task instead of the typical F, A, S because their study population presented seseo, described as the inability of the children of certain Spanish-speaking regions to differentiate between phonemes $[\Theta]$ and $[\mathrm{s}]$. This substitution limits the results to this type of sample with seseo and, therefore, cannot be extended to the general Spanish children population. In addition, several authors have concluded that the letters most used by the Spanish child population belong to the group P, M, R (Ardila \& Roselli, 1994) which are included at important neuropsychological batteries as Multilingual Aphasia Examination (Benton \& Hamsher, 1989) and NEPSY II (Korkman, Kirk \& Kemp, 2001). Thus, it would be interesting to carry out a qualitative analysis over this group of letters and compare their effectiveness in PVF tasks with respect to the typical F, A, S. Secondly, only used animals as semantic category although it has recently been shown that the use of several semantic categories in SVF tasks could modulate the use of grouping and jump strategies (Sunila, Rajashekhar \& Guddattu, 2018).

Motivated by these reasons, the present study emerged. The main objective was to explore the strategies (clustering and switching) of the VF by performing a qualitative analysis of SVF and PVF data recollected in two age groups (group 1: 8-9 years, group 2: 10-11 years) employing two semantic categories (animals; food or drinks) and two letter groups ( $\mathrm{F}$, A, S; P, M, R). Significant differences in VF performance between the age groups are expected and the insertion of new letters and semantic categories could modulate them. In PVF, a higher performance is expected in the letter group $\mathrm{P}$, M, R compared to F, A, S group. Likewise, differences between the age groups are expected in the SVF task by comparing the two proposed semantic categories.

\section{Method}

\section{Participants}

The sample consisted of 51 monolingual native Spanishspeaking children, distributed in two age groups (see Table 1):

- Group 1: A total of 33 children ages 8 to 9 years $(M=$ $8.55, S D=0.506$ ), of whom 21 were girls. 
- Group 2: A total of 18 children ages 10 to 11 years $(M=$ $10.39, S D=0.502)$, of whom 11 were girls.

The children were enrolled in several public schools of primary education in Murcia, proceeded from urban areas and middle socioeconomics levels. All participants were administered an extensive neuropsychological battery in order to ensure that they presented a cognitive profile within normal, i.e., intellectual levels within the normal expected range for their age, and no indicators of learning difficulties. Children were screened for a history of neurological or psychiatric problems, mental retardation, and learning disabilities from the information collected at school and from their parents. All the children attended school on a regular basis, did not need grade repeated neither corrective programs. The parents of children signed informed consent. Each child received a small gift (e.g., a box of pens or markers) after participation in the study.
Table 1

Demographic characteristics of the sample.

\begin{tabular}{lll}
\hline & \multicolumn{2}{c}{ Age group } \\
\cline { 2 - 3 } & $\begin{array}{l}\text { Group 1 } \\
\text { (aged 8-9) }\end{array}$ & $\begin{array}{l}\text { Group 2 } \\
\text { (aged 10-11) }\end{array}$ \\
\hline Number of participant & 33 & 18 \\
Age years (mean \pm SD) & $8.55(0.51)$ & $10.39(0.50)$ \\
Grade / Class & $3^{\circ}$ y $4^{\circ}$ & $4^{\circ}, 5^{\circ}$ y $6^{\circ}$ \\
Gender (Female/Male) & $21 / 12$ & $11 / 7$ \\
Handedness (Right/Left) & $30 / 3$ & $17 / 1$ \\
\hline
\end{tabular}

\section{Instruments}

Phonological (letters F, A, S, P, M and R) and Semantic Verbal Fluency Test were used. The test consists in asking the participant to recall all possible words starting with a given letter (phonological verbal fluency, PVF) or belonging to a given category (semantic verbal fluency, SVF) within 60 seconds, excluding proper names and alternate endings of the same word. Repetitions and intrusions were also excluded from the number of correct words, but not from the analysis of organizational strategies (groupings and jumps). The analysis of strategies used was performed according to the scoring rules proposed by Troyer et al. (1997) and Troyer (2000). The indicators used to score verbal fluency task are shown in Table 2 .

Table 2

Indicators used to score verbal fluency task.

Scoring method

\begin{tabular}{cl}
\hline Task type & Organizational strategies (Troyer \\
\hline Phonological (PVF) & Cluster: were defined as successive \\
Total score letter F & subcategory: \\
Total score letter A & Phonological cluster: \\
Total score letter S & - Words starting with the same \\
Total score letters FAS & two first letters or syllable \\
Total score letter P & - Words that rhyme \\
Total score letter M & - Start-end: words starting and \\
Total score letter R & ending with the same sound \\
Total score letters PMR & - Homonyms
\end{tabular}

Semantic (SVF)

Total score animals

Total score meals or drinks

Total score SVF ters.

\section{Semantic cluster:}

Animals: domestic/farm animals, animals of sierra, tropical/jungle animals, reptiles, flying animals, sea animals, insects and pairs of words associated by cultural influence (for example, elephantmouse).

- Meals or drinks: Meals: fruits, vegetables, cereals, desserts, appetizers, meats, fish, legumes, pasta dishes, sandwiches and hamburgers; Drinks: hot drinks, cold drinks, alcoholic drinks, refreshments.

Cluster size: the size of the cluster was counted beginning with the second word in each cluster. The mean cluster size was calculated by summing the size of each cluster and dividing by the number of clus-

Switches: calculated as the number of transitions between clusters, including single words.

\section{Procedure}

As part of a larger neuropsychology battery, tests of phonemic and semantic fluency were administered on an individual basis, in a quiet room in the school, to limit possible distractions. For the phonemic fluency test (PVF), participants were instructed to generate words beginning with $f$, $a$, $s, p, m$ or $r$, excluding proper names and alternate endings of the same word. For the semantic fluency test (SVF), participants were instructed to generate names of animals and names of meals or drinks. Sixty seconds was allotted for each of the six phonemic trials and two semantic trials. PVF task was administered first to aall the participants. Half of the sample made the letters in the order F, A, S followed by the letters P, M, R, while the other half did it in the reverse order. Next, they all completed the task of SVF explained above.

\section{Statistical analysis}

Univariate and multivariate analysis of variance (ANO$\mathrm{VA}$ and MANOVA) were performed to assess the effect of age on different fluency measures and the use of clustering and switching strategies. Compliance with homogeneity of variance assumption was confirmed before analysis. The association degree between variables was calculated using 
Pearson's correlation coefficient. Data processing and statistical analysis were performed using the Statistical Package for the Social Sciences (SPSS) version 24, and a statistical significance level below 0.05 was set.

\section{Results}

\section{Analysis of the total evocation in the PVF and SVF tasks}

Significant effects of age were seen by most verbal fluency measures administered (six letters for the phonological verbal fluency, independently and grouped in FAS and PMR, animals and meals or drinks for the semantic verbal fluency, also independently and grouped in total animals and meals or drinks).
For the PVF, the effect of age was observed both in the total production $\mathrm{F}+\mathrm{A}+\mathrm{S}(F(1,50)=10.641, p=.002)$, as in the total production $\mathrm{P}+\mathrm{M}+\mathrm{R}(F(1,50)=4.599, p=$ .037). In particular, the effect was found in the number of correct words emitted with the letter $\mathrm{F}(F(1,50)=5.467, p$ $=.024)$, with the letter $\mathrm{A}(F(1,50)=5.420, p=.024)$, with the letter $\mathrm{S}(F(1,50)=6.145, p=.017)$, with the letter $\mathrm{M}(F$ $(1,50)=8.848, p=.005)$ and a tendency to significance with the letter $\mathrm{P}(F(1,50)=3.943, p=.053)$. On the SVF, the total production Animals + Meals or drinks varied across group $(F(1,50)=11.003, p=.002)$, as well as animals and meals or drinks independently (Animals: $F(1,50)=9.879, p$ $=.003$; Meals or drinks: $F(1,50)=4.248, p=.045)$. In all of these the number of words generated was higher in the older group (Table 3).

Table 3

Phonemic and semantic fluency performance by age group.

\begin{tabular}{|c|c|c|c|c|c|c|}
\hline & & All & $\begin{array}{c}\text { Group } 1 \\
(8-9 \text { years) } \\
n=33\end{array}$ & $\begin{array}{c}\text { Group } 2 \\
(10-11 \text { years }) \\
n=18\end{array}$ & $F$ & $p$ \\
\hline \multirow[t]{8}{*}{ PVF } & Letter F & $\begin{array}{c}6.20(2.15) \\
{[2-11]}\end{array}$ & $\begin{array}{c}5.70(1.61) \\
{[2-9]}\end{array}$ & $\begin{array}{c}7.11(2.72) \\
{[3-11]}\end{array}$ & 5.467 & 0.024 \\
\hline & Letter A & $\begin{array}{c}6.67(2.36) \\
{[3-11]}\end{array}$ & $\begin{array}{c}6.12(2.26) \\
{[3-11]}\end{array}$ & $\begin{array}{c}7.67(2.27) \\
{[4-11]}\end{array}$ & 5.420 & 0.024 \\
\hline & Letter S & $\begin{array}{c}6.41(2.18) \\
{[1-11]}\end{array}$ & $\begin{array}{c}5.88(1.69) \\
{[3-10]}\end{array}$ & $\begin{array}{c}7.39(2.66) \\
{[1-11]}\end{array}$ & 6.145 & 0.017 \\
\hline & Total F+A+S & $\begin{array}{c}19.27(5.11) \\
{[11-31]}\end{array}$ & $\begin{array}{c}17.69(3.94) \\
{[11-26]}\end{array}$ & $\begin{array}{c}22.17(5.81) \\
{[11-31]}\end{array}$ & 10.641 & 0.002 \\
\hline & Letter P & $\begin{array}{c}8.45(2.71) \\
{[1-16]}\end{array}$ & $\begin{array}{c}7.91(2.75) \\
{[1-13]}\end{array}$ & $\begin{array}{c}9.44(2.41) \\
{[6-16]}\end{array}$ & 3.943 & 0.053 \\
\hline & Letter M & $\begin{array}{c}6.92(2.48) \\
{[2-12]}\end{array}$ & $\begin{array}{c}6.21(2.46) \\
{[2-11]}\end{array}$ & $\begin{array}{c}8.22(1.99) \\
{[4-12]}\end{array}$ & 8.848 & 0.005 \\
\hline & Letter R & $\begin{array}{c}6.31(2.13) \\
{[0-12]}\end{array}$ & $\begin{array}{c}6.36(2.39) \\
{[0-12]}\end{array}$ & $\begin{array}{c}6.22(1.59) \\
{[4-9]}\end{array}$ & 0.050 & 0.823 \\
\hline & Total $\mathrm{P}+\mathrm{M}+\mathrm{R}$ & $\begin{array}{c}21.69(5.61) \\
{[8-33]}\end{array}$ & $\begin{array}{c}20.48(6.04) \\
{[8-33]}\end{array}$ & $\begin{array}{c}23.89(3.99) \\
{[18-33]}\end{array}$ & 4.599 & 0.037 \\
\hline \multirow[t]{3}{*}{ SVF } & Animals & $\begin{array}{c}15.02(3.37) \\
{[10-25]}\end{array}$ & $\begin{array}{c}14.03(2.98) \\
{[10-20]}\end{array}$ & $\begin{array}{c}16.94(3.32) \\
{[12-25]}\end{array}$ & 9.879 & 0.003 \\
\hline & Meals or drinks & $\begin{array}{c}13.39(3.22) \\
{[6-25]}\end{array}$ & $\begin{array}{c}12.73(2.69) \\
{[6-18]}\end{array}$ & $\begin{array}{c}14.61(3.79) \\
{[10-25]}\end{array}$ & 4.248 & 0.045 \\
\hline & Total Animals + Meals or drinks & $\begin{array}{c}28.46(5.55) \\
{[17-40]}\end{array}$ & $\begin{array}{c}26.76(5.14) \\
{[17-38]}\end{array}$ & $\begin{array}{c}31.76(4.89) \\
{[25-40]}\end{array}$ & 11.003 & 0.002 \\
\hline
\end{tabular}

Data are means, typical deviations (in parentheses) and minimum-maximum range (brackets).

An ANOVA with repeated measures, followed by a post hoc Tukey test. demonstrated (Figure 1) that in both age group (8-9 years and 10-11 years). the number of correct words for each of the letters used in the task of PVF (letter $\mathrm{f}$ : $M=6.20, S D=2.15$; letter a: $M=6.67, S D=2.36$; letter s:
$M=6.41, S D=2.18$; letter $\mathrm{p}: M=8.45, S D=2.71$; letter $\mathrm{m}:$ $M=6.92, S D=2.48$; letter $\mathrm{r}: M=6.31, S D=2.13$ ) was lower than that produced on the categories in the task SVF (animals: $M=15.02, S D=3.37$; meals or drinks: $M=13.39$, $S D=3.22)(p \leq .001)$. 
Figure 1

Evocation in the tasks of PVF and SVF.

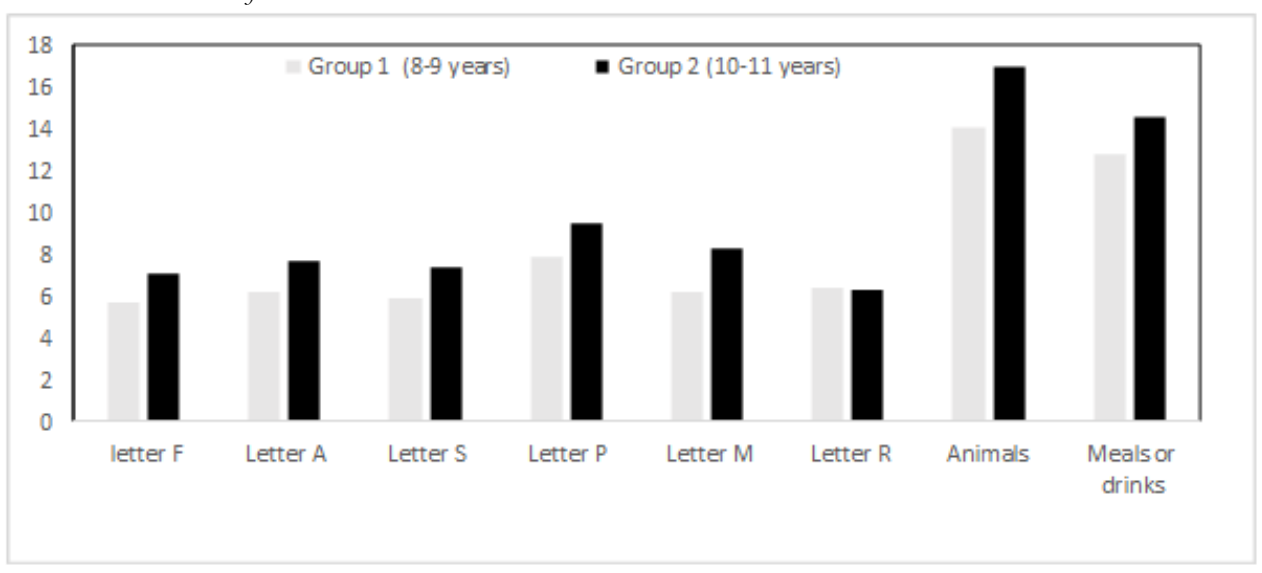

A repeated-measures ANOVA was used to analyse the effect of the letter used to measure the PVF. First, forms of PVF as entered as a within-subject factor $(\mathrm{F}+\mathrm{A}+\mathrm{S}$ and $\mathrm{P}$ $+\mathrm{M}+\mathrm{R}$ ), with group of age (group 1: 8-9 years; group 2: 10-11 years) as between-subject factor. Second, differences in performance between each of the letters were explored. In another similar ANOVA we study the effect of the category used to evaluate the SVF (animals and meals or drinks). For the PVF, significant main effect of form of PVF (FAS vs. PMR) was found. Comparisons indicated that performance was worse for the form FAS compared with the other form (FAS: $M=19.27, S D=5.11$; PMR: $M=21.69, S D=5.61$ ) $(p=.001)$. With regard to age, 8-9 years old performed worse for the form FAS compared with the other form (FAS: $M=17.69, S D=3.94$; PMR: $M=20.48, S D=6.04$ ) $(p=.001)$, but no significant difference was found between the forms of PVF (FAS vs. PMR) in the older group (10-11 years) (FAS: $M=22.17, S D=5.81$; PMR: $M=23.89, S D=$ 3.99) $(p=.129)$. Comparisons of the number of corrects for each of the letters (F, A, S, P, M and R) indicated a significant main effects of letter $(F(5,49)=10.751, p<.000)$ and age $(F(1,49)=8.651, p=.005)$. Specifically, the performance was better for the letter "P" compared with the other letters ( $p<.001$ in all cases) and was better for the letter "M" compared with the letter " $F$ " $(p=.013)$ and "R" $(p=.032)$. With regard to age, 8-9 years old performed better when asked to produce words with the letter "P" compared to the rest of the letters $(p \leq .001)$, while in the group of 10 to 11 years old the number of correct words with the letter "P" was greater than with the letters F, S and R $(p \leq .001)$.

For the SVF, significant main effect of category (animals vs. meals or drinks) was found. Comparisons indicated that performance was better for the category of animals compared with the other category (animals: $M=15.02, S D=$ 3.37; meals or drinks: $M=13.39, S D=3.22)(p=.003)$. With regard to age, the results were the same as in the case of the two forms of the task PVF. Only the differences between the semantic categories in the younger group (8-9 years) were significant (animals: $M=14.03, S D=2.98$; meals or drinks: $M=12.73, S D=2.69)(p=.004)$ (see Figure 2).

Figure 2

Evocation in the forms of PVF (FAS vs. PMR) and SVF (Animals vs. Meals or drinks).

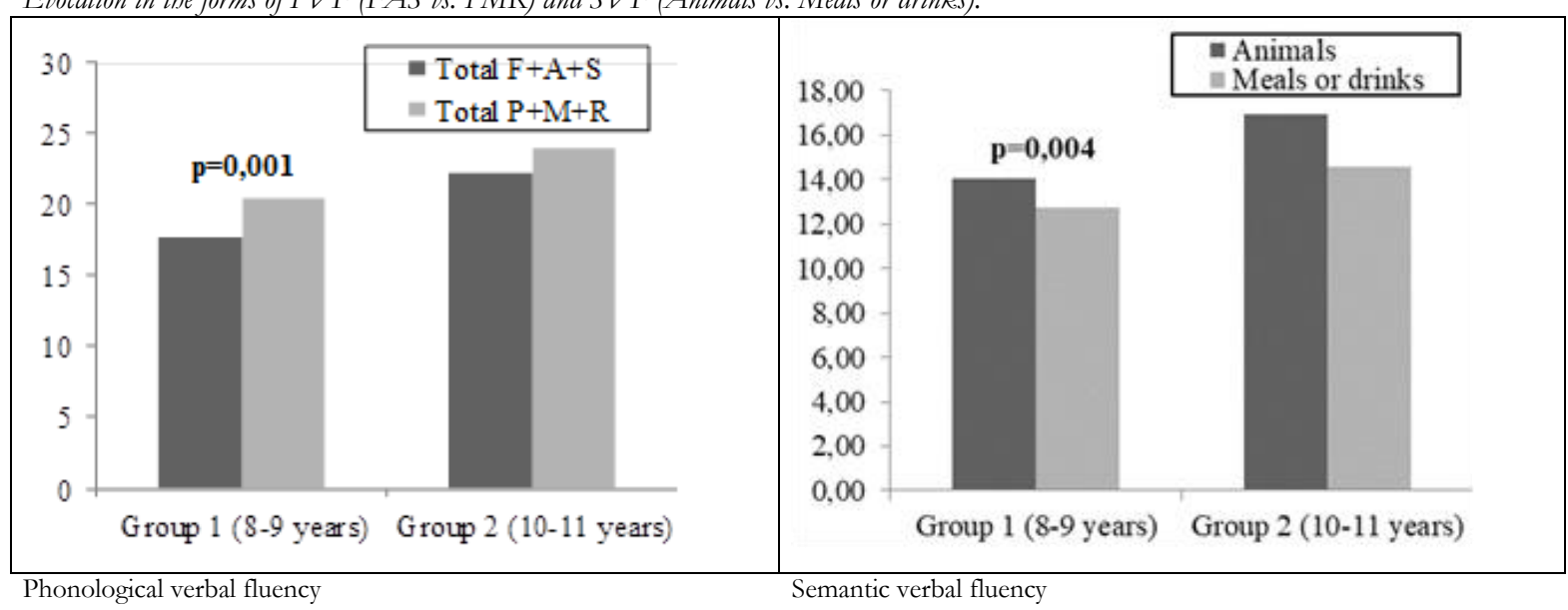




\section{Analysis of organizational strategies}

For the PVF, the data suggest significant differences favoring the older group in terms of number of switches when the FAS form of the phonological task was analyzed $(F(1,50)=$ 11.106, $p=.002)$, and a tendency to significance when analyzing the PMR form of the task $(F(1,50)=3.529, p=$ .066). No differences between groups in terms of the number of clusters and the mean cluster size were found for the two forms of phonological task (FAS and PMR). For the
SVF, age differences for the number of cluster were observed when the category meals or drinks of the semantic task was analyzed $(F(1,50)=4.214, p=.045)$, showing greater number of cluster older children. Within this same category no significant differences were found in the mean cluster size or in the number of switches. When the category "animals" of the semantic task was analyzed, the two groups did not differ significantly (number of cluster, mean cluster size and number of switches) (see Table 4).

Table 4

Organizational strategies for the tasks of PVF and SVF.

\begin{tabular}{|c|c|c|c|}
\hline & $\begin{array}{c}\text { Group } 1 \\
(8-9 \text { years }) \\
n=33\end{array}$ & $\begin{array}{c}\text { Group } 2 \\
(10-11 \text { years }) \\
n=18\end{array}$ & $p$ \\
\hline \multicolumn{4}{|l|}{ Phonological verbal fluency } \\
\hline Form $\mathrm{F}+\mathrm{A}+\mathrm{SNumber}$ of clusters & $\begin{array}{c}2.78(1.56) \\
{[0-6]}\end{array}$ & $\begin{array}{c}3.55(1.79) \\
{[1-7]}\end{array}$ & .117 \\
\hline Mean cluster size & $\begin{array}{c}2.89(1.67) \\
{[0-6]}\end{array}$ & $\begin{array}{c}3.13(1.17) \\
{[1-6]}\end{array}$ & .658 \\
\hline Number of Switches & $\begin{array}{c}10.70(3.27) \\
{[5-17]}\end{array}$ & $\begin{array}{c}14.72(5.24) \\
{[6-25]}\end{array}$ & .002 \\
\hline Form $\mathrm{P}+\mathrm{M}+\mathrm{RNumber}$ of clusters & $\begin{array}{c}4.91(2.01) \\
{[1-10]}\end{array}$ & $\begin{array}{c}5.22(2.16) \\
{[1-10]}\end{array}$ & .606 \\
\hline Mean cluster size & $\begin{array}{c}3.82(1.48) \\
{[1-6.75]}\end{array}$ & $\begin{array}{c}4.25(2.25) \\
{[2.33-10]}\end{array}$ & .417 \\
\hline Number of Switches & $\begin{array}{c}11.30(4.43) \\
{[1-22]}\end{array}$ & $\begin{array}{c}13.72(4.32) \\
{[3-22]}\end{array}$ & .066 \\
\hline \multicolumn{4}{|l|}{ Semantic verbal fluency } \\
\hline AnimalsNumber of clusters & $\begin{array}{c}3.50(1.18) \\
{[1-6]}\end{array}$ & $\begin{array}{c}4.06(1.52) \\
{[2-7]}\end{array}$ & .126 \\
\hline Mean cluster size & $\begin{array}{c}2.49(1.44) \\
{[1-8]}\end{array}$ & $\begin{array}{c}2.47(1.27) \\
{[1.3-6]}\end{array}$ & .975 \\
\hline Number of Switches & $\begin{array}{c}5.48(2.06) \\
{[1-9]}\end{array}$ & $\begin{array}{c}6.29(3.02) \\
{[1-13]}\end{array}$ & .269 \\
\hline Meals or drinksNumber of clusters & $\begin{array}{c}2.79(1.32) \\
{[0-6]}\end{array}$ & $\begin{array}{c}3.61(1.46) \\
{[2-7]}\end{array}$ & .045 \\
\hline Mean cluster size & $\begin{array}{c}1.39(0.71) \\
{[0-3.5]}\end{array}$ & $\begin{array}{c}1.32(0.32) \\
{[1-2]}\end{array}$ & .662 \\
\hline Number of Switches & $\begin{array}{c}7.82(1.83) \\
{[5-11]}\end{array}$ & $\begin{array}{c}8.83(2.15) \\
{[5-14]}\end{array}$ & .081 \\
\hline
\end{tabular}

Note: Data are means, typical deviations (in parentheses) and minimum-maximum range (brackets).

[5-14]

Meals or drinks: $r=.781 ; p<.01)$, as well as with the num-

Correlations among organizational strategies and total PVF (FAS vs. PMR) and SVF (Animals vs. Meals or drinks)

A correlational analysis was carried out to study the relationship between the number of correctly evoked total words and the use of the different organizational strategies (number of cluster, mean cluster size and number of switches), both for the PVF (FAS and PMR forms) as for the SVF (category animals and food or drinks). In the two forms of the PVF (F $+\mathrm{A}+\mathrm{S}$ and $\mathrm{P}+\mathrm{M}+\mathrm{R}$ ), and in the two categories used to measure the SVF, significant and positive correlations were found between the number of total words in each of those variables with the number of cluster in them (FAS: $r=.433$, $p<.01$; PMR: $r=.641, p<.01$; Animals: $r=.699, p<.01$; ber of switches (FAS: $r=.901, p<.01$; PMR: $r=.840, p<$ .01 ; Animals: $r=.544, p<.01$; Meals or drinks: $r=.768, p<$ .01). For the relationship between the mean cluster size and the number of total words evoked, only significant and positive correlations were found for the two forms of the PVF (FAS: $r=.380, p<.01$; PMR: $r=.288, p<.05$ ), but not for the two categories used to measure the SVF (Animals and Meals or drinks: $p>.05)$.

\section{Discussion}

The purpose of this study was to explore organizational strategies (clusters and switching) of the verbal fluency of Spanish children in two age groups (group 1: 8-9 years, group 2: 10-11 years) employing different semantic catego- 
ries (animals; food and drinks) and letter groups (F, A, S; P, $\mathrm{M}, \mathrm{R})$. The main results in the present study showed that: (a) SVF performance was better than PVF in the all of groups; (b) both SVF and PVF are better in older children specifically for FAS group of letters, M letter and all of semantic categories but not differences were found in $\mathrm{P}$ neither $\mathrm{R}$ letters; (c) younger children group showed better results for the the form PMR compared to FAS; in addition, this group evoked more words in the animal category than in the meals and drinks category; (d) older children used more switches (specifically in FAS and marginally in PMR) and more clusters for the drinks and meals category in comparisons with younger children. Finally, positive correlations between the number of words evoked and the number of organizational strategies for both VF tasks were found here. Then, these results will be discussing.

Firstly, results in SVF were better than in PVF task, in line with previous studies using children and adult population (Riva, Nichelli, \& Devoti, 2000). This suggests that word generation according to the phonological principle (PVF) implies more searching effort being more difficult than the SVF task (Riva et al., 2000). These results could be explained by the function of language organization. Phonological tasks require suppressing the habit of using words in a way related to their meaning (Perret, 1974) and greater effort in terms of searching due to the generation of words based on a phonemic/orthographic criterion is unusual. In addition, PVF performance involves different processes, such as phonological implementation, categorical storage and the formation of grammatical organization networks that are not present in SVF achieving (Pulvermüller, 2001). Conversely, semantic fluency is primarily based on semantic associations and meaning of words, specific inhibitory processes would not be required, leading to an easier retrieval of words. According to Riva et al. (2000) the major difficulty of phonological tasks suggests higher organizational demands and strategic capabilities depending on the maturation of the frontal lobe. Supporting this hypothesis of different processes involved in each condition, neuroimaging studies have shown the activation of different brain areas according to the semantic or phonological task type. Semantic fluency tasks would be more dependent on temporal lobe regions while phonological tasks would preferentially activate frontal lobe regions (Baldo, Schwartz, Wilkins, \& Dronkers, 2006; Martin et al., 1994; Mummery, Patterson, Hodges, \& Wise, 1996). Moreover, Szatkowska, Grabowska, and Szymanska (2000) found that the phonological and semantic fluency are mediated by different cerebral regions of the prefrontal cortex; the phonological fluency would be influenced by the left dorsolateral prefrontal cortex, while the semantic fluency might depend on the left and right dorsolateral prefrontal cortex and the right ventromedial areas. Taken together, different scores in both tasks are expected.

In respect to age factor, quantitative analysis revealed a larger difference between the 8-9- and 10-11-year-olds in both SVF and PVF. Specifically, older children obtained bet- ter results, in terms of evoked words, in both tasks than younger children group, according with previous works (Filipetti et al., 2011; Nieto et al., 2008). Precisely, older children were better in the both semantic categories than younger children (e.g., older children evoked 18 animals word compared to 14 animals' words which were pronounced by younger children, average data similar to those found in normative studies). On the one hand, this could be explained by the kind of semantic category. Thus, previous works found similar results than here with animal category but not for fruit category (Filipetti et al., 2011) indicating that the semantic category employed could be a modulating factor in this topic as will be mentioned bellow. On the other hand, several authors considered that this improvement with increasing age resulting from the lexicon-semantic memory development (Kavé, Kigel, \& Kochva, 2008; Riva et al., 2000; Sauzéon et al., 2004). Exactly, they affirm that the development of semantic fluency is more stable at 10 to 12 years of age as is reflected in these results (Riva et al., 2000; Sauzéon et al., 2004). Additionally, the performance with the $\mathrm{F}, \mathrm{A}, \mathrm{S}$ letters was better in the older children group than in the younger group, according to other studies (García et al., 2012; Nieto et al. 2008). Paying attention to the P, M, R letters group, only differences between both age groups were observed in the $\mathrm{M}$ letter and a marginal tendency to significance was observed in P letter, following other works (García et al., 2012; Nieto et al., 2008; Marino \& Alderete, 2010). From the best of our knowledge, there are no studies that use the letter R to evaluate PVF. However, the no difference associated with age especially for the $\mathrm{R}$ performance could be explained by two reasons. First, $\mathrm{R}$ letter is associated with an easier pronunciation in the Spanish language (specific sample language) compared to other languages and, therefore, it presents high basal levels of production which could imply less differences due to age. Second, it is probably that the pronunciation process of $\mathrm{R}$ letter is not related to maturational processes of frontal lobe, i.e., the evocation of this letter did not depend on development of frontal networks. These are hypothesis that that cause the need to explore this issue further.

For the explanation of the results in verbal fluency tasks, not only demographic variables such as age are important, but also the measures that are selected to measure it. The analysis showed that younger children group evoked more words in the form PMR (vs. FAS) and in the animal category (vs. meals and drinks). Further, in the study of the differences between the letters used for the measurement of phonological verbal fluency, the letter P showed superior yields at all ages studied. In line with these results, Strauss, Sherman and Spreen (2006) argued that the selection of the letters during the phonological verbal fluency task is of great importance because it determines the difficulty of the task. Thus, when Spanish speakers are evaluated, and according to the analysis of the difficulty of the letters, some authors suggest the use of the letters $\mathrm{P}, \mathrm{M}$ and $\mathrm{R}$ to measure phonological verbal fluency (Artiola, Hermosillo, Heaton and Pardee, 
1999). Few studies offer normative data used in the task of phonological verbal fluency for children and adolescents in Spanish-speaking populations, opting mainly for classical letters (i.e., $\mathrm{F}, \mathrm{A}$ and $\mathrm{S}$ or $\mathrm{M}$ ) and it is not usual to provide comparative data between the form most used to measure verbal fluency (letters F, A and S) and other forms (F, A and M, P, M and R, P and M) in these populations (Beltrán Dulcey and Solís-Uribe, 2012; Butman et al., 2000; Filippetti and Allegri, 2011; García et al., 2012; Nieto et al., 2008; Olabarrieta et al., 2017; Oliveira et al., 2016; Roselli et al., 2004). In this sense, Oliveira et al (2016), reported better performance for words that began with the letters $\mathrm{F}$ and $\mathrm{M}$ than for words that began with the vowel A. On the other hand, and with respect to the task of semantic verbal fluency is frequent the use of the category "animals". Other semantic categories reported in the literature to measure semantic verbal fluency include types of transport, fruits, vegetables, foods, drinks, clothing, professions, musical instruments, colors (Lezak et al., 2004). Our results are consistent with those found in other studies that indicate that the category of "animals" is easier than others such as fruits, vegetables and clothes (Roselli et al., 2009; Oliveira et al., 2016). The category "food and drinks" as a single entity has been used less and we do not know studies comparing its performance with that obtained in other categories. The differences between the categories could be explained in terms of category familiarity, as already noted (Koren et al., 2005). This question requires more research. One implication of these results is that performance on one form of the test or on one semantic category cannot be accurately interpreted using norms based on the other form or semantic categories. Similarly, parallel tests cannot be considered if they are used in pre- and postintervention evaluation of cognitive function. In addition, it is necessary to investigate the effects of the forms used to measure phonological verbal fluency and the semantic categories used to measure semantic verbal fluency at different ages because the effect can be seen at earlier ages and not in older children, as we have observed in our study. This may be related to the maturational development of executive functions and vocabulary. In younger children, the choice of letters for phonological verbal fluency and categories may be more important because, due to their development, executive skills and vocabulary are lower, as these functions develop older children may have results more similar between letters and the semantic categories used. Our results support the use of the letters $\mathrm{P}$ and $\mathrm{M}$ in Spanish-speaking children as well as the category of animals, at least in young children (8-9 years).

Additionally, the performance on the verbal fluency tasks involves the use of strategies such as groupings and jumps (Baldo et al., 2001; Troyer, 2000). The first strategy is described as the generation of sets of semantically associated words (semantic clusters) or phonologically (phonologic clusters), with two measured variables, the cluster size and the cluster number. The second strategy refers to the moment in which the subject feels a category as exhausted, desists and changes to another category (jumps), at both semantic and phonological levels. As regard as the cognitive processes associated with both strategies, groupings depend on the state of semantic memory, while jumps depend on executive components such as the subject's cognitive flexibility, mental search ability, degree of inhibition, and the ability to modify their responses in the course of the evaluation; without remaining stuck in a category (Sauzèon et al., 2004; Troyer, 2000). The positive correlations found between the number of words evoked and the number of organizational strategies (clustering and switching) for both VF tasks, suggests that both strategies explain the variations in verbal fluency tasks, which, by operating in conjunction, would optimize task performance (Troyer, 2000; Troyer et al., 1997) and are congruent with the results reported in previous developmental studies (Filippetti \& Allegri, 2011; Koren et al., 2005; Nieto et al., 2008). When the strategies employed in relation to PVF tasks were studied, a correlation between the number and size of phonemic clusters and switching strategies and total score was observed. For SVF tasks, our results indicate that the total score was more associated with the number of clusters and switches. However, we did not find a significant association between semantic cluster size and the total number of words generated. These results could be explained by the processes that underlie these two types of tasks, lexicalsemantic processing and executive processing. Findings from numerous studies support the probable relation of verbal fluency to both language and executive function (Aita, Beach, Taylor, Borgogna, Harrell \& Hill, 2018), but the relative weight of each of these functions in the performance of phonological and semantic verbal fluency tasks could be different (Filippetti \& Allegri, 2011). The phonological tasks require suppressing the habit of using words in a way related to their meaning (Perret, 1974) and greater effort in terms of searching, requiring the implementation of a greater amount of cognitive resources, related to lexicon-semantic knowledge and semantic organization, along with higher level cognitive processes such as executive functions and attention. In later studies it may be interesting to study the relationships between measures of verbal fluency, multiple dimensions of executive functions and language functioning, especially knowledge of words, in school-age children.

Our results also indicate that organizational strategies in verbal fluency tasks are influenced by age. Older children did more switches on phonological verbal fluency tasks (specifically in FAS and marginally in PMR) and more clusters for the semantic verbal fluency measure with "drinks and meals" category in comparisons with younger children. These results can be interpreted as indicative of the development of prefrontal functions, specifically with the development of greater cognitive flexibility that allows older children to use more effective search strategies, especially in phonological verbal fluency tasks and in the semantic task "food and drinks". As regard with phonological verbal fluency tasks, as indicated by Nieto et al (2008), the indicators of the capacity of change (number of clusters and jumps), experience a greater devel- 
opment from 8-9 years to 10-11 years (Nieto et al., 2008). Our results are similar to those found by other studies for this task (Filippetti \& Allegri, 2011; Koren et al., 2005; Nieto et al., 2008; Sauzeon et al., 2004). However, the results obtained with the category "animals" indicating that younger children perform the same as older children could be explained by the fact, already pointed out in other works, that changes in semantic verbal fluency tasks are more progressive and more extreme groups than ours are needed to find differences in organizational strategies (for example, children 6-7 years old compared to children 10-11 years old) (Nieto et al., 2008). The lack of data for the "food and drinks" category makes it impossible for us to contrast the results obtained, that is, a greater number of clusters in older children. This question requires more research.

From our knowledge this is the first time that both groups of letters were faced in a PVF task under a clustering

\section{References}

Aita, S. L., Beach, J. D., Taylor, S. E., Borgogna, N. C., Harrell, M. N., \& Hill, B. D. (2008). Executive, language, or both? An examination of the construct validity of verbal fluency measures. Applied Neuropsychology Adult, 26(5), 441-451.

Ardila, A., \& Rosselli, M. (1994). Development of language, memory, and visuospatial abilities in 5 - to 12 -year-old children using a neuropsychological battery. Developmental Neuropsychology, 10, 97-120.

Artiola, L., Hermosillo, D., Heaton, R., and Pardee, R. E. (1999). Manual de normas y procedimientos para la batería neuropsicológica en español. M. Press Tucson

Azuma, T. (2004). Working memory and perseveration in verbal fluency. Neuropsychology, 18(1), 69-77.

Baldo, J. V., Shimamura, A. P., Delis, D. C., Kramer, J., \& Kaplan, E. (2001). Verbal and design fluency in patients with frontal lobe lesions. Journal of the International Neuropsychological Society, 7, 586-596.

Baldo, J. V., Schwartz, S., Wilkins, D., Dronkers, N. F. (2006). Role of frontal versus temporal cortex in verbal fluency as revealed by voxelbased lesion symptom mapping. Journal of the International Neuropsychological Society, 12(6), 896-900.

Begeer, S., Wierda, M., Scheeren, A. M., Teunisse, J. P., Koot, H. M., \& Geurts, H. M. (2014). Verbal fluency in children with autism spectrum disorders: Clustering and switching strategies. Autism, 18(8), 1014-1018.

Beltrán Dulcey, C., \& Solís-Uribe, G. (2012). Evaluación Neuropsicológica en adolescentes: Normas para población de Bucaramanga. Revista Neuropsicología, Neuropsiquiatría y Neurociencias, 12(2), 77-93.

Benton, A., \& Hamsher, K. S. (1989). Multilingual aphasia examination. University of Iowa.

Brocki, K. C., \& Bohlin, G. (2004). Executive functions in children aged 6 to 13: A dimensional and developmental study. Developmental neuropsychology, 26(2), 571-593.

Butman, J., Allegri, R. F., Harris, P. \& Drake, M. (2000). Fluencia verbal en español. Datos normativos en Argentina [Verbal fluency in Spanish. Regulatory data in Argentina]. Medicina, 60 (5), 561-564.

Catani, M., Mesulam, M. M., Jakobsen, E., Malik, F., Martersteck, A., Wieneke, C., ... \& Rogalski, E. (2013). A novel frontal pathway underlies verbal fluency in primary progressive aphasia. Brain, 136(8), 2619-2628.

Filippetti, V. A., \& Allegri, R. F. (2011). Verbal fluency in Spanish-speaking children: Analysis model according to task type, clustering, and switching strategies and performance over time. The Clinical Neuropsychologist, 25(3), 413-436.

Fischer, M., Barkley, R. A., Edelbrock, C. S., Smallish, L. (1990). The adolescent outcome of hyperactive children diagnosed by research criteria: II. Academic, attentional, and neuropsychological status. Journal of Consulting and Clinical Psychology, 58(5), 580-588. and switching analysis, proposing the groups for the category "meals and drinks" for use in the qualitative analysis of organizational strategies. Among studies focused on normative data employed the classic letters (i.e., F, A, and S) in the PVF, while in the SVF it is often common to use the category "animals". Sometimes it is useful to have parallel tests that allow successive or longitudinal measurements, for example, to measure the effectiveness of treatments.

The present study has a number of limitations that should be taken into account when interpreting these results. First, only children of ages ranging from 8 to 11 years were included. However, the performance equivalent to that of an adult in fluency tasks exceeds those ages. Second, a more valid design to study the development of verbal fluency can be a longitudinal and non-cross-sectional study like the one used by us.

García, E., Rodríguez, C., Martín, R., Jiménez, J. E., Hernández, S., \& Díaz, A. (2012). Test de fluidez verbal: Datos normativos y desarrollo evolutivo en el alumnado de primaria. European Journal of Education and Psychology, 5(1), 53-64.

Gourovitch, M. L., Goldberg, T. E., \& Weinberger, D. R. (1996). Verbal fluency deficits in patients with schizophrenia: Semantic fluency is differentially impaired as compared with phonological fluency. Neuropsychology, 10(4), 573-577.

Henry, J. D., \& Crawford, J. R. (2004). Verbal fluency deficits in Parkinson's disease: a meta-analysis. Journal of the International Neuropsychological Society, 10(4), 608-622.

Kave, G., Kigel, S., Kochva, R. (2008). Switching and clustering in verbal fluency tasks throughout childhood. Journal of Clinical and Experimental Neuropsychology, 30(3), 349-59.

Klenberg, L., Korkman, M., \& Lahti-Nuuttila, P. (2001). Differential development of attention and executive functions in 3 to 12 -year-old Finnish children. Developmental Neuropsychology, 20(1), 407-428.

Koren, R., Kofman, O., \& Berger, A. (2005). Analysis of word clustering in verbal fluency of school-aged children. Archives of Clinical Neuropsychology, 20, 1087-1104.

Korkman, M., Kemp, S. L., \& Kirk, U. (2001). Effects of age on neurocognitive measures of children ages 5 to 12: A cross-sectional study of 800 children from the United States. Developmental Neuropsychology, 20(1), 331-354.

Ledoux, K., Vannorsdall, T. D., Pickett, E. J., Bosley, L. V., Gordon, B., \& Schretlen, D. J. (2014). Capturing additional information about the organization of entries in the lexicon from verbal fluency productions. Journal of clinical and experimental neuropsychology, 36(2), 205-220.

Lezak, M. D., Howieson, D. B., Loring, D. W., \& Fischer, J. S. (2004). Neuropsychological assessment. Oxford University Press.

Lozano, A., \& Ostrosky-Solís, F. (2006). Efecto de la edad y la escolaridad en la fluidez verbal semántica: Datos normativos en población hispanohablante. Revista Mexicana de Psicología, 23(1), 37-44.

Malloy-Diniz, L. F., Bentes, R. C., Figueiredo, P. M., Brañdao Bretas, D., da Costa-Abrantes, S., Parizzi, A. M., ... \& Salgado, J.V. (2007). Normalización de una batería de tests para evaluar las habilidades de comprensión del lenguaje, fluidez verbal y denominación en niños brasileños de 7 a 10 a ños: Resultados preliminares [Standardization of a battery of tests to assess language comprehension, verbal fluency and naming skills in Brazilian children aged 7 to 10 years: Preliminary results]. Revista de Neurología, 44(5), 275-280.

Marchetta, N. D., Hurks, P. P., Krabbendam, L., \& Jolles, J. (2008). Interference control, working memory, concept shifting, and verbal fluency in adults with attention-deficit/hyperactivity disorder (ADHD). Neuropsychology, 22(1), 74. 
Marino, J. \& Alderete, A. (2010) Valores Normativos de Pruebas de Fluidez Verbal Categoriales, Fonológicas, Gramaticales y Combinadas y Análisis Comparativo de la Capacidad de Iniciación. [Normative Values of Categorial, Phonological, Grammatical and Combined Verbal Fluency Tests and Comparative Analysis of initiation capacity]. Revista de Neuropsicologia, Neuropsiquiatría y Neurociencias, 10(1), 82-93.

Marino, J., \& Diaz-Fajreldines, H. (2011). Categorical, phonological and grammatical verbal fluency tasks in children: executive and semantic factors. Revista chilena de Neuropsicología, 6(1), 48-55.

Marino, J., Acosta Mesas, A., \& Zorza, J. P. (2011). Control ejecutivo y fluidez verbal en población infantil: Medidas cuantitativas, cualitativas y temporales [Executive control and verbal fluency in children: quantitative, qualitative and temporal measures]. Interdisciplinaria, 28(2).

Martin, A., Wiggs, C. L., Lalonde, F., Mack, C. (1994). Word retrieval to letter and semantic cues: a double dissociation in normal subjects using interference tasks. Neuropsychologia, 32(12), 1487-94.

Matute, E., Rosselli, M., Ardila, A., \& Morales, G. (2004). Verbal and nonverbal fluency in Spanish-speaking children. Developmental Neuropsychology, 26, 647-660.

Mielnik, A., Łockiewicz, M., \& Bogdanowicz, M. (2015). Semantic and phonological verbal fluency in students with dyslexia. Acta Neuropsychologica, 13(3).

Milner, B. (1964). Some effects of frontal lobectomy in man. In J. M. Warren \& K Akert (Eds.), The frontal granular cortex and behavior (pp. 313-334). McGraw-Hill.

Mummery, C. J., Patterson, K., Hodges, J. R., Wise, R. J. (1996). Generating 'tiger' as an animal name or a word beginning with T: differences in brain activation. Proceedings of the Royal Society B. Biological Sciences, 263(1373), 989-95.

N’Kaoua, B., Lespinet, V., Barsse, A., Rougier, A., \& Claverie, B. (2001). Exploration of hemispheric specialization and lexicosemantic processing in unilateral temporal lobe epilepsy with verbal fluency tasks. Neuropsychologia, 39, 635-642.

Nieto, A., Galtier, I., Barroso, J., \& Espinosa, G. (2008). Fluencia verbal en niños españoles en edad escolar: Estudio normativo piloto y análisis de las estrategias organizativas. Revista de Neurología, 46(1), 2-6.

Olabarrieta Landa, L., Landa Torre, E., López-Mugartza, J. C., Bialystok, E., \& Arango-Lasprilla, J. C. (2017). Verbal fluency tests: Developing a new model of administration and scoring for Spanish language. NeuroRehabilitation, 41(2), 539-565.

Oliveira, R.M., Mograbi, D. C., Gabrig, I.A., \& Charchat Fichman, H. (2016). Normative data and evidence of validity for the Rey Auditory Verbal Learning Test, Verbal Fluency Test, and Stroop Test with Brazilian children. Psychology \& Neuroscience, 9(1), 54-67.

Perret, E. (1974). The left frontal lobe of man and the suppression of habitual responses in verbal categorical behaviour. Neuropsychologia, 12, 323330.

Prigatano, G. P., Gray, J. A., \& Lomay, V. T. (2008). Verbal (animal) fluency scores in age/grade appropriate minority children from low socioeconomic backgrounds. Journal of the International Neuropsychological Society, 14(1), 143-147.

Pulvermüller, F. (2001). Brain reflections of words and their meaning. Trends in Cognitive Sciences, 5(12), 517-524.

Raboutet, C., Sauzeon, H., Corsini, M.-M., Rodrigues, J., Langevin, S., \& N'Kaoua, B. (2010). Performance on a semantic verbal fluency task across time: Dissociation between clustering, switching, and categorical exploitation processes. Journal of Clinical and Experimental Neuropsychology, 32, 268-280.

Riva, D., Nichelli, F., \& Devoti, M. (2000). Developmental aspects of verbal fluency and confrontation naming in children. Brain and Language, 71 267-284.

Rosselli, M. C., Matute, E. V., Ardila, A. A., Botero, V. G., Tangarife, G. S., Echevarría, S. P., ... \& Ocampo, P. A. (2004). Neuropsychological assessment of children: a test battery for children between 5 and 16 years of age. A Colombian normative study. Revista de neurologia, 38(8), 720 731.

Rosselli, M., Tappen, R., Williams, C., Salvatierra, J., \& Zoller, Y. (2009). Level of education and category fluency task among Spanish speaking elders: number of words, clustering, and switching strategies. Aging, Neuropsychology, and Cognition, 16(6), 721-744.

Sauzéon, H., Lestage, P., Raboutet, C., N'Kaoua, B., \& Claverie, B. (2004). Verbal fluency output in children aged $7-16$ as a function of the production criterion: Qualitative analysis of clustering, switching processes, and semantic network exploitation. Brain and Language, 89, 192-202.

Sergeant, JA., Geurts, H., Oosterlaan, J. (2002). How specific is a deficit of executive functioning for attention-deficit/hyperactivity disorder? $\mathrm{Be}$ havioural Brain Research, 130(1-2), 3-28.

Schwartz, S., \& Baldo, J. (2001). Distinct patterns of word retrieval in right and left frontal lobe patients: a multidimensional perspective. Neuropsychologia, 39(11), 1209-1217.

Smith-Spark, J. H., Henry, L. A., Messer, D. J., \& Zięcik, A. P. (2017). Verbal and non-verbal fluency in adults with developmental dyslexia: Phonological processing or executive control problems? Dyslexia, 23(3), 234-250.

Strauss, E., Sherman, E., \& Spreen, O. (2006). Verbal fluency. A compendium of neuropsychological tests, 499-526.

Sunila, J., Rajashekhar, B., \& Guddattu, V. (2018). Analysis of Verbal Fluency Output on Semantic Categories of 'Food' and 'Vehicle' in Typically Developing Malayalam Speaking Children. Psychology of Language and Communication, 22(1), 328-353.

Szatkowska, I., Grabowska, A., Szymańska, O. (2000). Phonological and semantic fluencies are mediated by different regions of the prefrontal cortex. Acta Neurobiologiae Experimentalis, 60(4), 503-8.

Tallberg, I. M., Carlsson, S., \& Lieberman, M. (2011). Children's word fluency strategies. Scandinavian Journal of Psychology, 52(1), 35-42.

Troster, A. I., Warmflash, V., Osorio, I., Paolo, A. M., Alexender, L. J., \& Barr, W. B. (1995). The roles of semantic networks and search efficiency in verbal fluency performance in intractable temporal lobe epilepsy. Epilepsy Research, 21, 19-26.

Troyer, A. K. (2000). Normative data for clustering and switching on verbal fluency task. Journal of Clinical and Experimental Neuropsychology, 22(3), 370-378.

Troyer A.K., Moscovitch, M., and Winocur, G. (1997). Clustering and switching as two components of verbal fluency: evidence from younger and older healthy adults. Neuropsychology, 11(1), 138-146.

Tucha, O., Mecklinger, L., Laufkötter, R., Kaunzinger, I., Paul, G., Klein, H., \& Lange, K. (2005). Clustering and switching on verbal and figural fluency functions in adults with attention deficit hyperactivity disorder. Cognitive Neuropsychiatry, 10(3), 231-248.

Van der Elst, W., Hurks, P., Wassenberg, R., Meijs, C., \& Jolles, J. (2011). Animal Verbal Fluency and Design Fluency in school aged children: Effects of age, sex, and mean level of parental education, and regression-based normative data. Journal of Clinical \& Experimental Neuropsy chology, 33(9), 1005-1015. 